\title{
Epidemiology of biopsy proven giant cell arteritis in northwestern Spain: trend over an 18 year period
}

Abstract

Objective-In Europe giant cell arteritis (GCA) is more common in Scandinavian countries than in southern regions. Epidemiological studies on GCA in other more distant countries have indicated a progressive increase in incidence. A regular cyclical pattern in incidence of GCA over 20 years has been reported in Olmsted County (Minnesota, USA). In contrast, no cyclical fluctuation has been recently reported in Sweden. To investigate further the epidemiology of GCA in southern Europe the trend in incidence and fluctuations of this vasculitis over 18 years in the Lugo region of northwestern Spain were examined.

Methods-A retrospective study of biopsy proven GCA diagnosed between 1 January 1981 and 31 December 1998 at a single hospital for a well defined population of almost 250000 people. Annual incidence was calculated for the whole group of patients and for men and women separately. Monthly variations, annual peaks of incidence, and trend in the incidence of biopsy proven GCA with and without polymyalgia rheumatica (PMR) were also examined.

Results-One hundred and sixty one Lugo residents were diagnosed with biopsy proven GCA between 1981 and 1998. The proven GCA between 1981 and 1998. The average annual incidence for the popula(men $11.00 / 100000$, women $9.57 / 100000$ ). A progressive increase in the incidence in br presive both men and women was seen. In men there was an annual increase of $8 \% \mathbf{( 9 5 \%}$ CI $4 \%$ to $13 \%$; $<0.0001)$. In women the annual increase was $11 \%(95 \%$ CI $5 \%$ to $17 \%$; $<0.0001)$. The overall annual increase for men and women was $10 \%(95 \%$ CI $6 \%$ to $14 \%$; $p<0.0001)$. No seasonal pattern or peaks in the incidence were seen. During the period 1981-94 GCA was more common in men than in women. In contrast, during the last years of study the increase in incidence was higher in women. In women the annual ratio of incidence of GCA with PMR/incidence of GCA without PMR was generally higher than 1 . However, in men the annual ratio was initially 1 but decreased gradually, indicating a progressive decrease in the proportion of men with biopsy proven GCA associated with PMR.
Conclusion-In northwestern Spain there has been a progressive increase in GCA incidence. As seen in other countries where GCA is more common, during the past few years the increase in incidence has been mainly due to a higher number of new cases in women.

(Ann Rheum Dis 2001;60:367-371)

Giant cell (temporal) arteritis (GCA) is a vasculitis of unknown cause, usually affecting large and medium sized vessels in the elderly. ${ }^{1-3}$ It is the most common systemic vasculitis in Western countries. ${ }^{45}$ In Europe GCA is more common in Scandinavian countries ${ }^{267}$ than in southern regions. ${ }^{5-10}$ Epidemiological studies on GCA in more distant countries have indica in mave in ${ }^{11-13}$ progressice Savarani et al reported a Salvarani et al reported a regular cyclical pattern in incidence of GCA over a 20 year period. ${ }^{14}$ In contrast, no cyclical fluctuation has been recently reported in Sweden. ${ }^{15}$ To investigate further the epidemiology of GCA in outhern Europe we examined the trend and fuctuations of this vasculitis over an 18 year period in the Lugo region of northwestern Spain.

Patients and methods

All patients diagnosed with biopsy proven GCA, seen in the department of medicine of the Hospital Xeral-Calde (Lugo, Spain) between January 1981 and December 1998, were included in this study. The Hospital XeralCalde is the only referral centre for a mixed rural $(60 \%)$ and urban population of almos 250000 people living in the Lugo region of northwestern Spain. The main characteristics of the Lugo population have been reported The ${ }^{5}{ }^{16}$ This population is Cav casoid of Celtic origin, ${ }^{17}$ is relatively static, and no important migration has occurred in the area during the past two decades. In 1991 the population aged 50 and older in Lugo comprised 99800 (men 46\%; women 54\%). It constituted $41 \%$ of the whole population of ation is greater than in the rest of Spain. During the past 10 years the population fell by 500

Patients with suspected GCA were sent to the hospital by general practitioners or they self referred to the emergency unit. A temporal artery biopsy was performed in all patients with tions of GCA. Segments longer than $2.5 \mathrm{~cm}$ were generally obtained. In 

Table 1 Average annual incidence of biopsy proven giant cell arteritis in Lugo (Spain). Number of cases by age and sex
and incidence per 100000 population aged 50 and older for the period 1981-98

\begin{tabular}{|c|c|c|c|c|c|c|}
\hline & \multicolumn{2}{|c|}{ Women } & \multicolumn{2}{|l|}{ Men } & \multicolumn{2}{|l|}{ Total } \\
\hline & Cases & $\begin{array}{l}\text { Incidence }(95 \% \mathrm{CI}) \\
\left(\times 10^{-5}\right)\end{array}$ & Cases & $\begin{array}{l}\text { Incidence }(95 \% \text { CI }) \\
\left(\times 10^{-5}\right)\end{array}$ & Cases & $\begin{array}{l}\text { Incidence }(95 \% \text { CI }) \\
\left(\times 10^{-5}\right)\end{array}$ \\
\hline $50-59$ & 1 & 1.35 (0.00 to 3.24$)$ & 2 & $1.72(0.00$ to 3.54$)$ & 3 & $1.54(0.33$ to 2.75$)$ \\
\hline $60-69$ & 13 & $4.11(1.98$ to 6.24$)$ & 15 & $5.22(1.98$ to 8.47$)$ & 28 & $4.64(2.40$ to 6.88$)$ \\
\hline $70-79$ & 47 & 19.05 (10.28 to 27.82$)$ & 43 & 23.06 (13.10 to 33.03$)$ & 90 & 20.78 (13.33 to 28.23$)$ \\
\hline$>80$ & 21 & 15.01 (7.09 to 22.93$)$ & 19 & $20.72(6.40$ to 35.04$)$ & 40 & $17.48(8.75$ to 26.20$)$ \\
\hline Total & 82 & 9.57 (5.56 to 13.58$)$ & 79 & $11.00(8.97$ to 13.54$)$ & 161 & 10.24 (8.13 to 12.58$)$ \\
\hline
\end{tabular}

$\mathrm{CI}=$ confidence interval

patients with polymyalgia rheumatica (PMR), without any clinical manifestation of GCA, biopsies were usually considered if patients had constitutional syndrome or the erythrocyte sedimentation rate (ESR - by Westergren's method) was greater than $80 \mathrm{~mm} / 1 \mathrm{st} \mathrm{h}$, or both. ${ }^{18} 19$ Patients were diagnosed as having biopsy proven GCA if histological examination of the temporal artery showed interruption of the internal elastic laminae with infiltration of mononuclear cells into the arterial wall with or without giant cells. ${ }^{5}{ }^{16}$ Patients were classified as having biopsy proven GCA associated with PMR if, in addition to the pathological abnormalities in the temporal artery described above, they met the following criteria: $(a)$ aged 50 or older at the onset of symptoms; (b) severe and bilateral pain associated with morning stiffness (lasting at least 30 minutes) in at least two out of three areas: neck, shoulder, and/or pelvic girdles; $(c)$ ESR at the time of diagnosis of at least $40 \mathrm{~mm} / 1 \mathrm{st} \mathrm{h}$; and (d) exclusion of other diseases that may present with polymyalgia manifestations or mimic PMR except GCA. ${ }^{13} 16182021$

Twenty nine biopsy negative patients fulfilled the American College of Rheumatology (ACR) classification criteria for GCA. ${ }^{22}$ In these patients headache and PMR were common presenting symptoms. In contrast, abnormal temporal artery on physical examination, jaw claudication, and ischaemic visual manifestation were less common than in patients with biopsy proven GCA ${ }^{23}$ Temporal patients with biopsy proven GCA. 39 parients

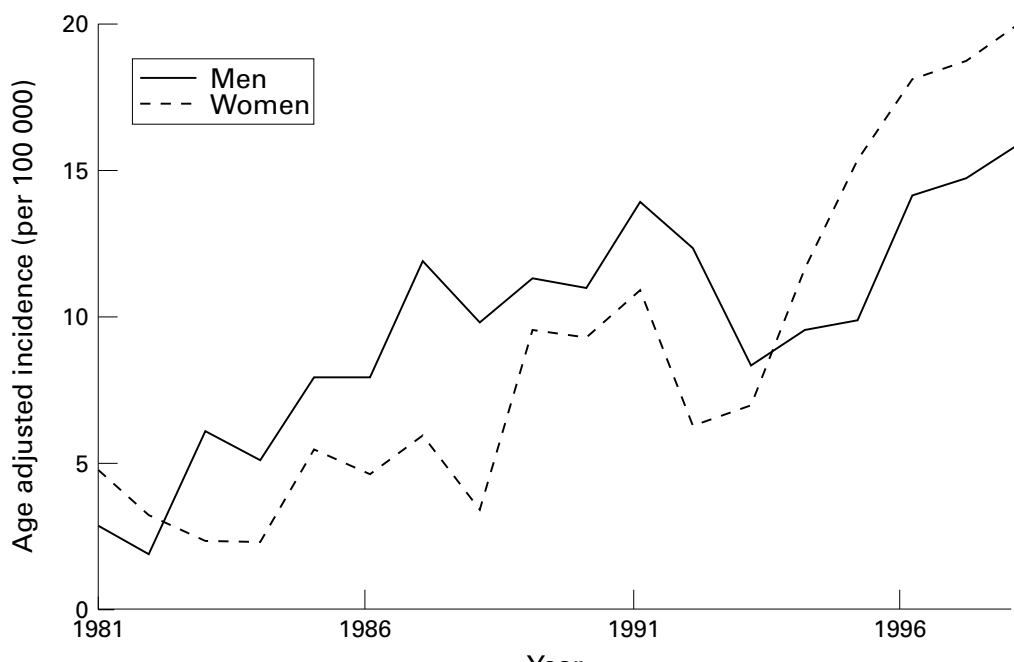

Figure 1 Incidence of biopsy proven giant cell arteritis (GCA) by sex in Lugo, Spain (1981-98). Diring the period 1981-94 GCA was mo (GCA) the last years the increase of incidence was higher in women. with PMR without any clinical manifestation of GCA. Only $8(9 \%)$ had positive biopsy results. The positive/negative temporal artery biopsy ratio did not change significantly during the period of study.

STATISTICAL ANALYSIS

The target population was based on the census. The population distribution was provided by he Instituto Nacional de Estadística (INE). In the Lugo region, people grouped by age and sex were estimated by exponential interpolation from census data. In Spain the censuse were taken every 10 years when the last figure of the year was zero. More recently, censuses ove been carried out in years whose last figure 1. In addition, municipalites assess the sess the population every five years. The population between censuses is established by extrapolation using the formula provided by the INE $P_{t}=P_{0}(1+r)^{t}$, where $P_{t}$ is the population to be calculated, $P_{0}$ is the reference population, $t$ is the time lag to be extrapolated, and $r$ is the rowth rate of the popula period. Incidence rates standary period. Incidence rates standardised by age were calculated by a direct method using th European population as standard; the European standard was preferred to the World standard because it better represents a developed country's population. Rates are reported as cases for $10^{5}$ population aged 50 or older.

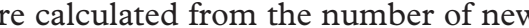
cases observed/the estimated population aged 50 and older. The annual incidence adjusted for age was calculated as a five year moving average reflecting the slow random changes. To analyse relations between age and calendar year (as explanatory variables) and GCA incidence rate (as outcome variable) three The first one only considers age as explanatory and it assumes that the GCA incidence = exponential $\left(\beta_{0}+\beta_{1} \times\right.$ age $)$; exponential $\left(\beta_{1}\right)$ would then be interpreted as the ratio corresponding to each year of age.

The second model assumes that the GCA incidence $=$ exponential $\left(\beta_{0}+\beta_{1} \times\right.$ age $+\beta_{2} \times$ calendar year); then exponential $(\beta$ ) would be interpreted as before, and $\beta_{2}$ as the rate ratio interpreted as before, and $\beta_{2}$

Finally, the third model is the same as that used by Petursdottir et $a l^{15}$ and assumes that the GCA incidence $=$ exponential $\left(\beta_{0}+\beta_{1} \times\right.$ age + $\beta_{2} \times$ calendar year $+\beta_{3} \times$ calendar year $^{2}$ ).

Goodness of fit of all three models were compared by the likelihood ratio. To analyse whether any season or any month of onset of 


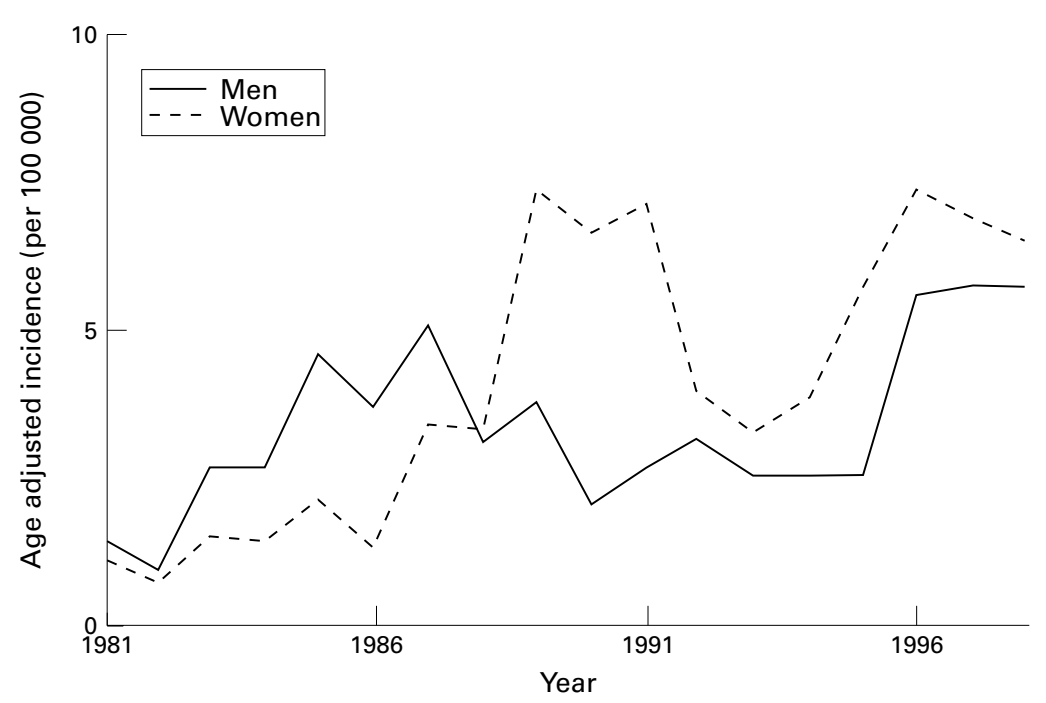

Figure 2 Incidence of biopsy proven giant cell arteritis (GCA) associated with polymyalgia rheumatica (PMR) in Lugo, Spain by sex (1981-98). Since 1987 there has been a trend towards an
associated with PMR.

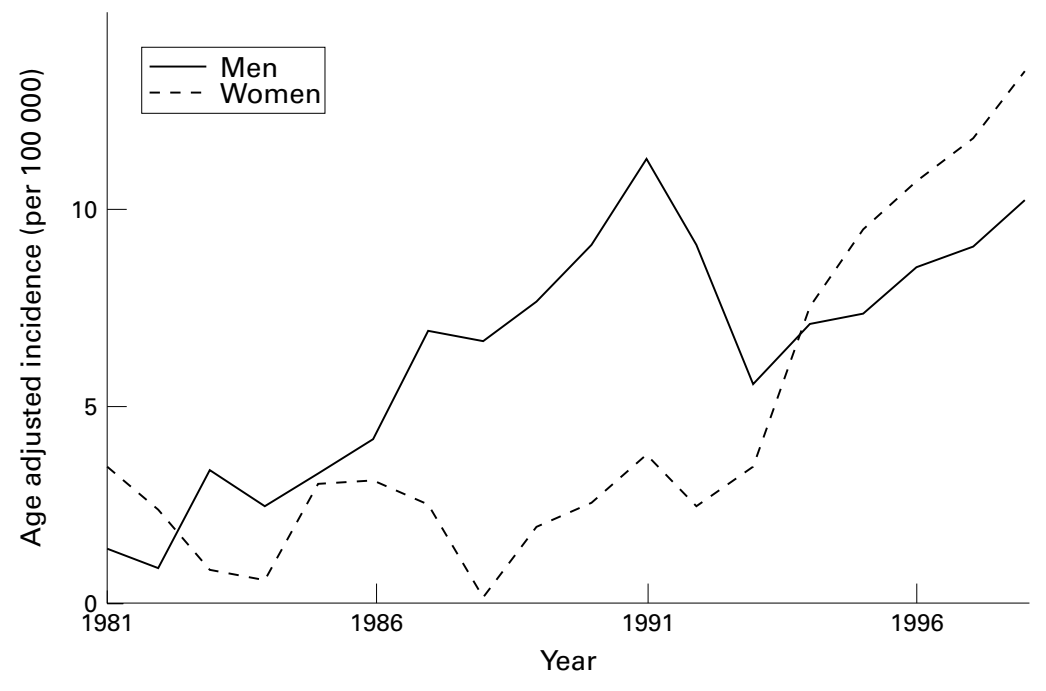

Figure 3 Incidence of biopsy proven giant cell arteritis (GCA) without polymyalgia has been seen to be more common in women than in men.

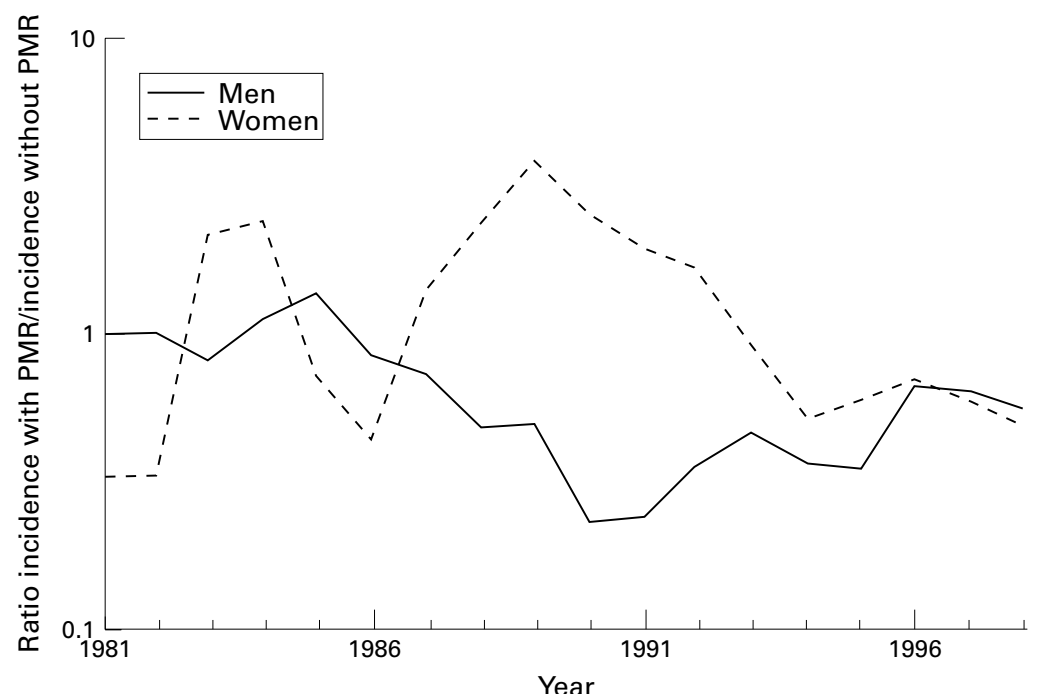

Figure 4 Annual incidence of biopsy proven giant cell arteritis (GCA) with polymyalgi rheumatica (PMR)/annual incidence of GCA without PMR ratio in Lugo, Spain by sex (1981-98). In men, unlike in women, the ratio was initially 1 but has tended to decrease symptoms in particular was more common, a $\chi^{2}$ test was used. This test was used to compare the number of cases observed and expected. To investigate if there were non-random peaks in he annual incidence, the actual number of cer the cases predicted by Poisson regression. A statistical analyses were performed with th software Stata Intercooled, release 6 (Stata Corporation, College Station, Texas, USA).

\section{Results}

The overall average annual incidence for the 18 year period was $10.24 / 100000$ people aged 50 and older (men 11.00/100 000, women 9.57। 100 000). Table 1 shows the adjusted rates for the population aged 50 and older by age and sex. In both men and women biopsy proven GCA was more common in patients older than 70

Based on the second model described in "Patients and methods" the risk ratio (RR) per year in men was 1.08 (95\% CI 1.04 to 1.13 ; $\mathrm{p}<0.0001)$. The RR per year in women was 1.11 (95\% CI 1.05 to $1.17 ; \mathrm{p}<0.0001)$. For men there was an annual increase in incidence adjusted by age of $8 \%(95 \%$ CI $4 \%$ to $13 \%$; $\mathrm{p}<0.0001)$. In women the annual increase was $11 \%$ (95\% CI $5 \%$ to $17 \%$; $<<0.0001$ ). As a (1) whole the $10 \%(95 \%$ CI $6 \%$ to $14 \%$; women was $10 \%$ (95\% CI $6 \%$ to $14 \%$; $\mathrm{p}<0.0001)$. The highest incidence in both men and women aged 50 and older was seen in 1998 men 17.4/100 000 population, women 21.6/ 100 000).

No seasonal pattern was seen ( $\mathrm{p}$ values for men 0.20 , women 0.64 , and total 0.32 ). Also, no increase of the incidence of GCA in any month in particular (considered as the month month in particular (considered as the month
of onset of symptoms) was seen ( $p$ values for men 0.53 , women 0.64 , and total 0.57 ).

Figure 1 shows the incidence of GCA by sex. A progressive increase in the incidence was seen in both men and women. During the period 1981-94 GCA was more common in men. In contrast, during the last few years of the study the increase in incidence was higher in women. However, no peaks in the annual incidence of GCA were found.

In Lugo isolated PMR (not associated with GCA) is known to be more common in women. ${ }^{18}$ Because of this, we analysed GCA with and without PMR separately. Figure 2 shows that biopsy proven GCA associated with PMR was more common in men until 1987. PMR was more common in men until 1987.
Since then, there has been a trend towards an increase in the number of women with biopsy proven GCA associated with PMR. Likewise, until 1994 GCA without PMR was more common in men. Since then GCA without PMR has also been found to be more common in women (fig 3). To further investigate possible changes in the incidence of biopsy proven GCA examined the annual incidence of GCA with PMR/annual incidence of GCA without PMR ratio. Figure 4 shows that in most years the ratio in women was higher than 1 (more cases of biopsy proven GCA associated with PMR than those without PMR). In men, however, 


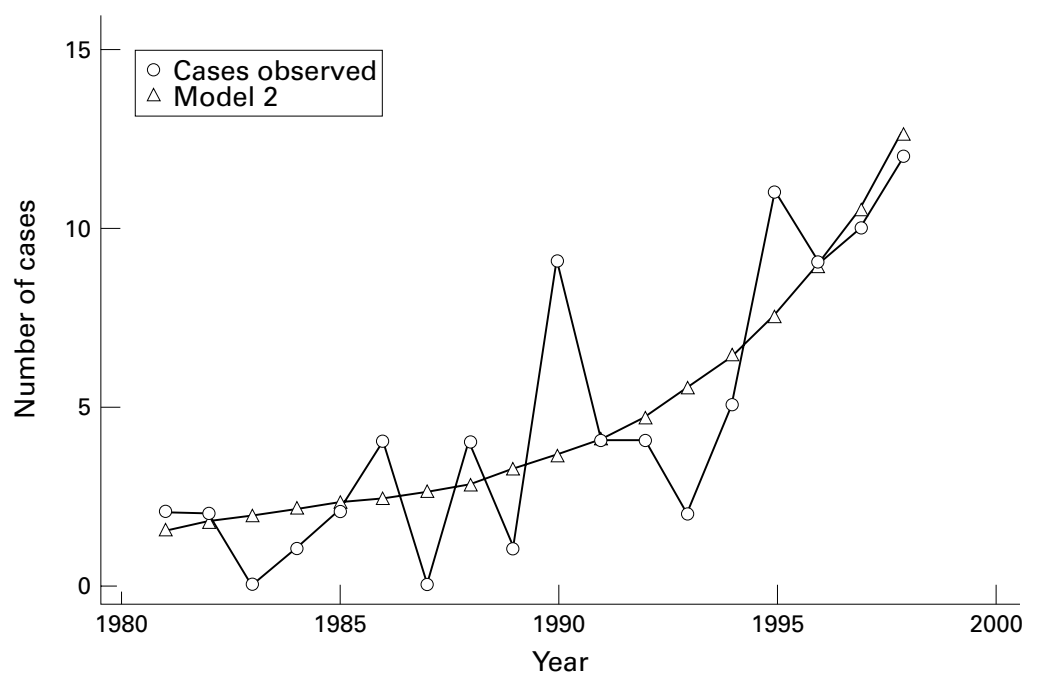

Figure 5 Number of biopsy proven giant cell arteritis (GCA) cases observed (circles) and those expected in women from Lugo, Spain (1981-98) by Poisson regression using as explanatory variables age and calendar year (triangles). The figure shows that new increases in GCA incidence are expected for women.

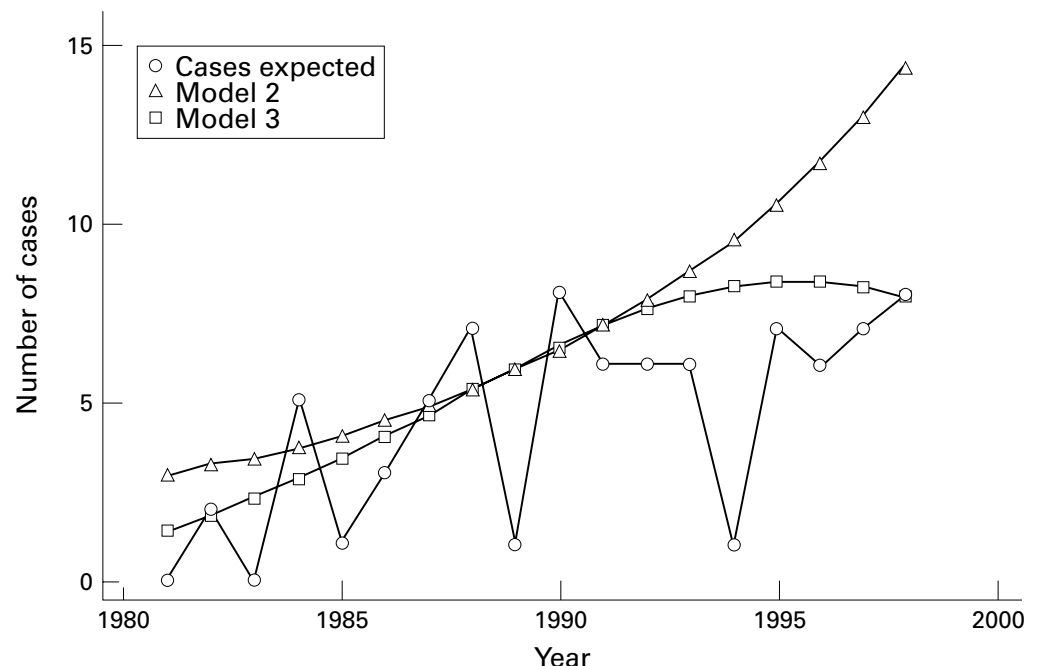

Figure 6 Number of biopsy proven giant cell arteritis cases (GCA) observed (circles) and those expected in men from Lugo, Spain (1981-98) by Poisson regression using as (the figure suggests that the peak of the incidence of GCA in men has been reached.

unlike women, the ratio was initially 1 but it has tended to decrease gradually and indicates the progressive decrease in the proportion of men with PMR.

In women, the second model developed by Poisson regression that included age and calendar year as explanatory variables fits the data. Thus fig 5 suggests that new increases in GCA incidence are expected for women. Also, the addition of a third explanatory term (calendar year ${ }^{2}$ ) did not improve the goodness of fit. However, in men the second model did not adjust well, and it was necessary to include a calendar year ${ }^{2}$ term (third model). Figure 6 suggests that the peak of the incidence in men suggests that the
has been reached.

Discussion

Giant cell arteritis does not always require a positive temporal artery biopsy. As shown in patients with biopsy proven GCA, we have also seen a progressive increase in the incidence of patients with negative temporal artery biopsies who were classified as GCA according to the criteria proposed by the ACR. Moreover, as contralateral temporal artery biopsies were not considered in all cases if the first biopsy was cormal, it is possible that some cases missed because a positive temporal arter biopsy was a requirement for inclusion in this study.

The incidence of GCA is higher in Scandinavian countries and in Olmsted County, Minnesota, whose population has a Scandinavian background, than in other European countries 126711141524 In these countries the annula . people aged 50 and older. In southern Europe, in contrast, the incidence is lower than $12 / 100000$ people aged 50 and older. ${ }^{5}$ Within southern Europe differences in the incidence also exist. For example, in northwest Spain the incidence of GCA is almost twice as high as that seen in northern Italy. ${ }^{5} 8$

The incidence of GCA increases with latitude in the northern hemisphere, with at least a twofold increase in incidence in Scandinavian countries compared with Lugo. The present study, however, also supports a progressive increase in incidence in southern Europe. Such an increase has also been seen in seen in other countries, ${ }^{11} 15$ the increase in the incidence of GCA in Lugo was associated with a constan relation between positive and negative biopsies. ${ }^{13}$ However, the rheumatologists from Lugo were puzzled by the predominance of GCA in men between 1981 and $1990{ }^{16}$ To our mence, and unlike reports from oth ies, that decade was lower than in men. This could not be explained by sex differences in the structure of the population. However, although a progressive increase of the incidence in both sexes was found over this 18 year study, in the last few years the trend has been towards a pro roven GCA associated with PMR and in thos with GCA unassociated with PMR. Moreover, in the past few years the GCA associated with PMR in men has tended to decrease gradually. A declining trend in the annual incidence of GCA in men was also seen in Olmsted County and Israel. ${ }^{11}{ }^{12}$ Variations in the annual incience of GCA with peaks every seventh yea ave been reported in Olmsted County. ${ }^{14}$ However, in keeping with Petursdottir et al, ${ }^{15}$ no rhythmic pattern in the annual incidence of GCA was seen in the Lugo region. Elling et al reported evidence of simultaneous fluctuations of the incidence of GCA and PMR in different regions of Denmark, suggesting an epidemic occurrence of a precipitating infectious agent. ${ }^{25}$ Seasonal distribution of the disease has also been reported. Based on the date of biopsy, peaks of incidence in late winter and autum were found by Petursdottir et al..$^{15}$ Also, based on the onset of symptoms, peaks of incidence were found during the summer months in . ${ }^{126}$ In Scotland other peaks in January and May were seen by 
Jonasson et al. ${ }^{27}$ However, in this study we found no seasonal pattern for GCA distribution in Lugo.

Despite discrepancies in the presence of peaks of incidence and seasonal patterns among different studies, most investigations show a progressive increase in the incidence of show a progressive increase in the incidence of
the disease. A greater awareness of GCA may the disease. A greater awareness of GCA may
account for an increase in the diagnosis of cases in earlier stages of its natural history. Also, unknown environmental factors may play an important part in affecting the incidence of GCA as they may mor the disease in a genetically predisposed population.

In conclusion, this study confirms a progressive increase in the incidence of GCA and a trend towards a greater increase of this vasculitis among women in southern Europe over an 18 year period.

1 Nordborg E, Nordborg C, Malmvall BE, Andersson R, Am 1995;21:1013-26.
Bengtsson B-A, Malmvall B-E. The epidemiology of giant cell arteritis including temporal arteritis and polymyalgia and eye complications. Arthritis Rheum 1981;24:899-904. 3 Calamia KT, Hunder GG. Clinical manifestations of giant cell (temporal) arteritis. Clin Kheum Dis 1980,6:389-403. vasculitides. Baillieres Clin Rheumatol 1997;11:191-217.
González-Gay MA, Garcí-Porrúa C. Systemic vasculitis in González-Gay MA, García-Porrúa C. Systemic vasculitis in
adults in northwestern Spain, 1988-1997: clinical and epidemiologic aspects. Medicine (Baltimore) 1999;78:292-

6 Boesen P, Sorensen SF. Giant cell arteritis, temporal arter -

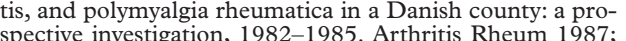
30:294-9.

7 Baldursson O, Steinsson K, Björnsson J, Lie JT. Giant cell arterits in Tceland. Ahe epidemiologic and histopathologic

8 Salvarani C, Macchioni P, Tartoni PL, Rossi F, Baricchi Castri C, et al. Polymyalgia rheumatica and giant cell

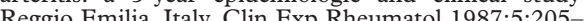

9 Salvarani C, Macchioni P, Zizzi F, Mantovani W, Rossi F, Castri C, et al. Epidemiologic and immunogenetic aspects

0 Barrier J, Pion P, Massari R, Peltier P, Rojouan J, Grollea JY. Approche epidémiologique de la maladie de Horton dans le départment de Loire-Atlantique: 110 cas en 10 an
1 Machado EB, Michet CJ, Ballard DJ, Hunder GG, Beard sota, 1950-1985. Arthritis Rheum 1988;31:745-9.

Sonnenblick M, Nesher G, Friedlander Y, Rubinow A. Giant cell arteritis in Jerusalem: a 12-year epidemiologic

3 González-Gay MA, Blanco R, Sánchez-Andrade A Vázquez-Caruncho M. Giant cell arteritis in Lugo, Spain: more frequent disease with fewer classic features. J
Rheumatol 1997:24:2166-70.

14 Salvarani C, Gabriel SE, O'Fallon WM, Hunder GG. The incidence of giant cell arteritis in Olmsted County, Minnesota: apparent fluctuations in a cyclic pattern. An

5 Intern Med 1995;123:192-4. epidemiology of biopsy-positive giant cell arteritis: special
reference top cyclic fluctuations. Rheumatology (Oxford) 1999;38:1208-12.

16 González-Gay MA, Alonso MD, Agüero JJ, Bal M rernandez-Cambitis in a northwestern area of Spain: study of 57 biopsy proven patients. J Rheumatol 1992;19:277-80, Dababneh A, González-Gay MA, García-Porrúa C, Hajeer A, Thomson W, Ollier W. Giant cell arteritis and polymyaHLA class II association. J Rheumatol 1998;25:2140-5. M, Dababneh A, Hajeer A, Ollier WER. The spectrum of polyndalgia $\mathrm{A}$, year-study. J Rheumatol 1999;26:1326-32.

19 González-Gay MA, García-Porrúa C, Vázquez-Carunch M. Polymyalgia rheumatica in biopsy-proven giant cell from isolated polymyalgia rheumatica. J Rheumatol 1998; 25:1750-5. 20 Chuang TY, Hunder GG, Ilstrup DM, Kurland LT. clinical study. Ann Intern Med 1982;97:672-80. 1 Cohen MD, Ginsburg WW. Polymyalgia rheumatica. Rheum Dis Clin North Am 1990;16:325-39.

Hunder GG, Bloch DA, Michel BA, Stevens MB, Arend Rheumatabre LHe et al. The American College of 3 Gonź́ Louzao VC, Rodriguez-Ledo P. Biopsy-negative giant cel ral artery biopsy. Semin Arthritis Rheum (in press).

Nordborg E, Bengtsson BA. Epidemiology of biopsy-prove giant cell arteritis (GCA). J Intern Med 1990;227:233-6. incidence of temporal arteritis and polymyalgia rheums the in different regions of Denmark; ass of mycoplasma pneumoniae infection. J Rheumatol 1996,

Kinmont PDC, McCallum DI. The etiology and course of Dermatol 1965;77:193-202.

27 Jonasson F, Cullen JF, Elton RA. Temporal arteritis. A 14-year epidemiological, clinical and prognostic study. 